\title{
Self-Report Measurement of Depression, Anxiety, and Stress Caused by COVID-19 Pandemic in Senior Undergraduate Dental Students
}

\author{
Gül Keskin ${ }^{1}$
}

${ }^{1}$ Department of Pediatric Dentistry, Faculty of Dentistry, Gaziantep University, Gaziantep, Turkey.

Correspondence: Gül Keskin, Department of Pediatric Dentistry, Faculty of Dentistry, Gaziantep University, Gaziantep, Turkey. E-mail: gulbeyret@hotmail.com

Academic Editor: Alidianne Fábia Cabral Cavalcanti

Received: 17 November 2020 / Review: 10 January 2021 / Accepted: 04 March 2021

How to cite: Keskin G. Self-Report measurement of depression, anxiety, and stress caused by COVID-19 pandemic in
senior undergraduate dental students. Pesqui Bras Odontopediatria Clín Integr. $2021 ; 21: e 0243$.
https://doi.org/10.1590/pboci.2021.102

https://doi.org/10.1590/pboci.2021.102

\begin{abstract}
Objective: To evaluate the effect of the COVID-19 pandemic on senior undergraduate dental students' psychological health by measuring depression, anxiety, and stress levels. Material and Methods: 259 fifthyear dental students participated in this study, including 156 females (60.2\%) and 103 males (39.8\%), aged 20-25. An online-based questionnaire was created, including a few questions about learning, postgraduation challenges, and fear of the virus exposure. Students were asked to define their acute anxiety state by visual facial anxiety scale (VFAS) and depression, anxiety, and stress levels by The Depression, Anxiety and Stress Scale (DASS-42). All data were analyzed statistically. Results: Participants stated online learning platforms were insufficient for clinical competence (91.5\%), the COVID-19 pandemic changed postgraduation career perspectives (29.3\%), and they feared exposure to COVID-19 while performing their profession $(82.6 \%)$. Acute anxiety levels of the students were recorded as $95.4 \%$ mild to highest. Mild to extremely severe depression, anxiety, and stress scores of the participants were $82.1 \%, 79.6 \%$, and $72.9 \%$, respectively. Higher mean values for all depression, anxiety, and stress parameters were obtained in females than males $(\mathrm{p}<0.05)$. Conclusion: Data showed that the psychological health of senior undergraduate dental students had been affected adversely due to the COVID-19 pandemic.
\end{abstract}

Keywords: COVID-19; Mental Health; Dental Students; Depression; Anxiety. 


\section{Introduction}

Coronavirus disease 2019 (COVID-19), caused by severe acute respiratory syndrome coronavirus 2, is an infectious disease that poses complex challenges for medical communities, research, and global public health by the emergence and rapid increase in the number of cases [1]. Since the home-confinement strategies and nationwide lockdowns implemented to prevent further disease transmission in most of the hit countries by COVID-19 after China, a wide fragment of the world's population is currently limited mainly to their homes [2]. While this strategy is an effective practice in controlling the spread of COVID-19, it could have adverse impacts on the economy and inhabitants' life. In a recent study, a high loss of household income and impaired quality of life in the general population have been reported due to the COVID-19 pandemic [3].

The challenges in teaching and learning by this unprecedented situation have been based on changing college students' lives, such as adjusting to new living circumstances, leaving campus, and adapting to online learning platforms. Courses such as artistic performance, labs, and/or practicums, including high levels of interaction and hands-on experiences, have been affected more adversely [4]. To master the theory is the first aim of dental education. The second is to gain clinical competence with patient care and performing therapeutic procedures. Clinical practice is realized by the undergraduate students themselves under the professional supervision of teachers [5]. Previous studies showed that dental students had higher levels of stress than the general population [6,7]. In dental education, which is a source of stress in itself, common challenges such as loss of learning opportunities, uncertainty in course requirements, lack of guidance, and fear of exposure to COVID-19 can enhance stress even more on dental students. The major disadvantage for senior undergraduate dental students is that clinical training cannot be sustained by direct patient care, which is a key component of the dental curriculum. This creates some concerns for students who are about to graduate in terms of professional knowledge and skills and in terms of performing the profession after graduation.

Stress, defined as the perception of discrepancy between environmental demands and individual capacities to fulfill those demands, can affect the course of both medical problems such as poor wound healing and high blood pressure and psychological conditions such as depression and anxiety [8]. The Depression, Anxiety and Stress Scale (DASS) is commonly used as a tool to quantitatively measure the three dimensions of psychological conditions in a concise, single, and comprehensive scale [6]. DASS was previously used in research related to the COVID-19 pandemic and its effectiveness was validated in different cultures [9-11]. In the DASS, the participants rate their experience of each over the past week by 42 negative emotional symptoms [12]. There are studies evaluating depression, anxiety, and stress of dental students by using DASS $[6,12]$. However, to our knowledge, there is no study on the psychological impact of COVID-19 on senior undergraduate dental students.

This study aimed to determine the concerns of senior undergraduate dental students about learning and professional competence and to evaluate their depression, anxiety, and stress levels with a commonly used scale (DASS-42) in the COVID-19 pandemic.

\section{Material and Methods}

Participants

All fifth-year dental students from the different faculties of dentistry in Turkey studied in the academic year 2020/2021 were invited to participate. Two hundred fifty-nine of the invited students participated in the study and entered the survey in September 2020. The group included 156 females (60.2\%) and 103 males (39.8\%), aged 20-25 years. This study was reviewed and approved by the Human Research 
Ethics Committee of Gaziantep University (2020/209). Participants provided consent to participate before the commencement of the survey.

\section{Questionnaire}

An online-based questionnaire was distributed to the participants through social media apps. The survey included a few questions: the effectiveness of online learning platforms for theoretical and practical education, whether the student makes an individual effort to support learning and what resources he/she uses to obtain the knowledge, what field he/she wants to serve after graduation and the effect of the pandemic in this request, financial concerns, and fear of exposure to COVID-19. Moreover, participants were asked to define their anxiety levels from 1 (none) to 6 (highest) using the visual facial anxiety scale (VFAS). Finally, the Turkish version of DASS-42 was performed. All data were self-reported.

The DASS-42, which is designed to measure the negative emotional states of depression, anxiety, and stress, is a questionnaire that includes three self-report scales with 42 items. Fourteen items present in each of the three scales, and include subscales of 2-5 items with similar content. The Depression scale assesses inertia, anhedonia, dysphoria, lack of interest/involvement, hopelessness, self-deprecation, and devaluation of life. The Anxiety scale assesses situational anxiety, subjective experience of anxious affect, skeletal muscle effects, and autonomic arousal. The Stress scale (items) is sensitive to levels of chronic non-specific arousal. It assesses nervous arousal, difficulty relaxing, irritable/over-reactive, being easily upset/agitated, and impatient. To rate the extent of depression, anxiety, and stress, participants are asked to use 4-point severity scales (from 0 to 3 ). The scores for the severity labels of the DASS have been demonstrated in Table 1.

Table 1. The scores for the severity labels of the DASS.

\begin{tabular}{lccc}
\hline Severity Label & Depression & Anxiety & Stress \\
\hline Normal & $0-9$ & $0-7$ & $0-14$ \\
Mild & $10-13$ & $8-9$ & $15-18$ \\
Moderate & $14-20$ & $10-14$ & $19-25$ \\
Severe & $21-27$ & $15-19$ & $26-33$ \\
Extremely Severe & $28+$ & $20+$ & $34+$ \\
\hline
\end{tabular}

Statistical Analysis

All analyses were performed by an SPSS 22.0 statistical software package (SPSS, Inc., Chicago, IL, USA). Descriptive statistics (percentages, frequencies, means, and standard deviations) were performed to assess the answers to questionnaires and levels of depression, anxiety, and stress among participants. The comparative analysis used a One-Sample T-Test.

\section{Results}

The questionnaire stating senior students' considerations about learning and post-graduation challenges was presented in Table 2. Participants reported that online learning platforms would not be sufficient for practical training $(91.5 \%)$. However, when evaluated in terms of learning, $56 \%$ of the participants argued that online learning platforms would not be sufficient, while $32 \%$ argued that learning would be similar with both methods. When the individual activities of the participants to support learning in the COVID-19 academy were questioned, it was reported that $29.7 \%$ of them studied from the sourcebooks. This was followed by online seminars and webinars (15.8\%), lecture notes $(15.8 \%)$, and online videos $(10 \%) .74(28.6 \%)$ of the participants stated that they did not make an individual effort to support learning. $29.3 \%$ of the participants 
stated that the COVID-19 pandemic changed their post-graduation career perspectives. While the work opportunities where the participants would like to work post-graduation were academy (41.3\%), private sector $(24.3 \%)$, public institution $(16.2 \%)$, respectively. Only $39(15.1 \%)$ of the participants stated that they were undecided. Most participants (48.6\%) stated that they would earn less money after graduation due to the COVID-19 pandemic. Furthermore, 82.6\% of them stated that they fear exposure to COVID-19 while performing their profession.

Table 2. Questionnaire of stating senior students' considerations about learning, professional skills, and post-graduation in the COVID-19 pandemic.

\begin{tabular}{|c|c|c|c|}
\hline Questions & $\begin{array}{l}\text { Yes } \\
\mathrm{N}(\%)\end{array}$ & $\begin{array}{c}\text { No } \\
\mathrm{N}(\%)\end{array}$ & $\begin{array}{c}\text { Similar } \\
\mathrm{N}(\%)\end{array}$ \\
\hline $\begin{array}{l}\text { Item } 1 \text { - Do you think learning with online learning platforms creates a problem in } \\
\text { terms of professional competence? }\end{array}$ & $145(56.0)$ & $31(12.0)$ & $83(32.0)$ \\
\hline $\begin{array}{l}\text { Item } 2 \text { - Do you think clinical training with online learning platforms creates a problem } \\
\text { in terms of professional competence? }\end{array}$ & $237(91.5)$ & $12(4.6)$ & $10(3.9)$ \\
\hline \multicolumn{4}{|l|}{$\begin{array}{l}\text { Item } 3 \text { - What were your individual activities to support the learning during the } \\
\text { COVID-19 pandemic? }\end{array}$} \\
\hline I attended training programs such as online seminars and webinars. & $41(15.8)$ & & \\
\hline I watched online videos & $26(10.0)$ & & \\
\hline I studied from sourcebooks. & $77(29.7)$ & & \\
\hline I studied from the lecture notes & $41(15.8)$ & & \\
\hline I did not do anything individually & $74(28.6)$ & & \\
\hline \multicolumn{4}{|l|}{$\begin{array}{l}\text { Item } 4 \text { - Did the COVID-19 pandemic have an impact on your post-graduation career } \\
\text { perspective? (academy, public, private) }\end{array}$} \\
\hline Yes, I have changed my mind & $76(29.3)$ & & \\
\hline No, I have not changed my mind & $97(37.5)$ & & \\
\hline I am indecisive & $86(33.2)$ & & \\
\hline \multicolumn{4}{|l|}{ Item 5 - After graduation, which career would you like to evaluate on your profession? } \\
\hline Academic & $107(41.3)$ & & \\
\hline Public & $42(16.2)$ & & \\
\hline Private & $63(24.3)$ & & \\
\hline None & $8(3.1)$ & & \\
\hline I am indecisive & $39(15.1)$ & & \\
\hline \multicolumn{4}{|l|}{ Item 6 - How do you think the COVID-19 pandemic will affect your earning post-graduation? } \\
\hline I think I will earn more money. & $17(6.6)$ & & \\
\hline I think I will earn less money. & $126(48.6)$ & & \\
\hline I don't think there will be any different. & $62(23.9)$ & & \\
\hline I am indecisive & $54(20.8)$ & & \\
\hline Item 7 - Are you have a fear of exposure to COVID-19 in the profession? & Yes $(214 /$ & 82.6) No & $45 / 17.4)$ \\
\hline
\end{tabular}

The professional concern of participants caused by the COVID-19 Pandemic determined with VFAS was presented in Table 3. Most of the participants (42.5\%) exhibited the "highest" level of anxiety, while only $4.6 \%$ of the participants stated that they they did not fall under anxiety.

Table 3. Classification of professional concern caused by the COVID-19 Pandemic using the visual facial anxiety scale.

\begin{tabular}{lc}
\hline \multicolumn{1}{c}{ Classification } & $\mathrm{N}(\%)$ \\
\hline 1 (None) & $12(4.6)$ \\
2 (Mild) & $10(3.9)$ \\
3 (Mild-Moderate) & $18(6.9)$ \\
4 (Moderate) & $39(15.1)$ \\
5 (Moderate-High) & $70(27.0)$ \\
6 (Highest) & $110(42.5)$ \\
\hline
\end{tabular}


The number and percentage of participants' depression, anxiety, and stress were presented in Table 4. Of the participants, $59(16.5 \%)$ in depression, 81 (22.6\%) in anxiety, and $34(9.5 \%)$ in stress were labelled as "extremely severe". The mean values of depression, anxiety, and stress were 18.40, 16.37, and 19.48, respectively, in all participants. This indicated that the participants were "Moderate" label in terms of depression and stress, and "Severe" label in terms of anxiety. In the comparative analysis of the mean values of DASS by gender (Table 5), higher mean values were obtained in females compared to males, which was valid for all depression, anxiety, and stress parameters. This difference was statistically significant $(\mathrm{p}<0.05)$.

Table 4. The number and percentage of participants evaluated by depression, anxiety, and stress and mean values of DASS.

\begin{tabular}{lccc}
\hline \multicolumn{1}{c}{ Classification } & Depression & Anxiety & Stress \\
& $\mathrm{N}(\%)$ & $\mathrm{N}(\%)$ & $97(27.1)$ \\
\hline Normal & $64(17.9)$ & $73(20.4)$ & $28(7.8)$ \\
Mild & $37(10.3)$ & $15(4.2)$ & $55(15.4)$ \\
Moderate & $50(14.0)$ & $37(10.3)$ & $45(12.6)$ \\
Severe & $49(13.7)$ & $53(14.8)$ & $34(9.5)$ \\
Extremely Severe & $59(16.5)$ & $81(22.6)$ & $19.48(11.108)$ \\
Mean (Std. Deviation) & $18.40(11.328)$ & $16.37(12.000)$ & \\
\hline
\end{tabular}

Table 5. The mean of DASS values by gender and comparison each other statistically.

\begin{tabular}{clcc}
\hline Gender & Condition & Mean (Std. Deviation) & p-value \\
\hline Female $(\mathrm{n}=156)$ & Depression & $19.82(11.205)$ & 0.000 \\
& Anxiety & $18.53(11.854)$ & 0.000 \\
& Stress & $21.99(10.484)$ & 0.000 \\
\multirow{2}{*}{ Male $(\mathrm{n}=103)$} & Depression & $16.24(11.227)$ & 0.000 \\
& Anxiety & $13.11(11.527)$ & 0.000 \\
& Stress & $15.69(10.998)$ & 0.000 \\
\hline
\end{tabular}

$\mathrm{p}<0.05$ was considered significant.

\section{Discussion}

This study was planned to identify fifth-year dental students' concerns about learning, post-graduate career perspectives, financial difficulties and exposure risk of the virus in COVID-19 pandemic. The findings of the study are in line with studies reporting that the current COVID-19 pandemic had a significant negative impact on the mental health of university students [4,13-15]. In this study, acute [state] anxiety of the participants was identified with VFAS that is quick and easy to administer, and abnormal anxiety levels (mild to highest) were recorded as $95.4 \%$. Depression, anxiety, and stress states of the students' experience of each over the past week were evaluated with the DASS. The mean of the DASS data showed that the studied population was moderate level in terms of depression and stress, and a high level of anxiety. Moderate to extremely severe depression, anxiety and stress scores were $44.2 \%, 47.7$, and $37.5 \%$ of the participants, respectively. This was higher than scores $(21.34 \%, 34.19 \%$ and $28.14 \%$, respectively) obtained in the study of Odriozola-González et al. [16]. This difference may be due to the that this study included students, researchers, and administrative staff from different areas (Arts \& Humanities, Sciences, Health Sciences, Social Sciences and Law, and Engineering and Architecture) and the students from different educational year and levels (Undergraduate, Master, PhD., or Other).

In a systematic review that aimed to report on the effects of COVID-19 on psychological outcomes of the general population, relatively high rates of symptoms of depression (14.6\% to $48.3 \%$ ), anxiety (6.33\% to $50.9 \%$ ), and stress $(8.1 \%$ to $81.9 \%)$ were reported in the general population in Turkey, China, the US, Denmark, Nepal, Italy, Spain, and Iran. In this global meta-analysis, risk factors associated with adverse 
psychological health were reported to include younger age group ( $\leq 40$ years), unemployment, presence of chronic/psychiatric illnesses, student status, female gender, and frequent exposure to social media/news concerning COVID-19 [17]. Wang et al. [18] also presented lower psychological scores among the general population than the present study that the psychological changes were evaluated in a specific group. It seems senior dental students are at more risk psychologically than the general population.

In a previous study before the COVID-19 pandemic, abnormal levels (mild to extremely severe) of depression, anxiety and stress were identified in $55.9 \%, 66.8 \%$ and $54.7 \%$ of the 247 dental students, included from 2 nd to 5 th year of education, respectively [6]. In the present study, mild to extremely severe depression, anxiety and stress scores $82.1 \%, 79.6 \%$, and $72.9 \%$ of the participants, respectively. Although these two studies do not include the same sample, it can be said that the psychological health of dental students is deteriorating with the COVID-19 pandemic. Concerning dental students, who are in their last year of education, such as to graduate before achieving clinical competence, post-graduation financial difficulties and exposure risk to the virus may be predisposing factors in this increase. Cao et al. [15] indicated that anxiety symptoms of college students during pandemic were positively associated with effects on daily life, economic effects, and as well as delays in academic activities.

Aerosol emitted during routine dental practices increases the exposure risk to the COVID-19 of dentists, dental students in clinical practice, auxiliary staff, and patients by ocular transmission or inhalation of airborne particles [19]. The severity of the COVID-19 pandemic presents clear challenges worldwide in terms of dental education, despite available guidelines for the management of dental patients [20]. Therefore, most dental schools in Turkey, like all over the world, have also suspended clinical practices except for emergencies and have tried to provide learning with online platforms. Online learning systems involve facilitating two-way communication between teachers and students and the implementation of advancements in technology to deliver the learning content. Mukhtar et al. [2 1] reported that despite the online platforms have advantages such as accessibility, comfort, and remote learning, they also have limitations such as difficulty and inefficiency in maintaining academic integrity. To postpone direct patient care, which is a key component of the dental curriculum, has been the biggest challenge of virtual sessions as it cannot reflect close experience with patients [22]. This could be supported by this study that $91.5 \%$ of the students reported would not be enough the efficacy of the online learning platforms in clinical dental training. However, in a study by Kharma et al. [23] evaluating the anxiety and stress of students about returning to training in dental colleges, it was reported that $85 \%$ of participants felt anxiety and stress. $67 \%$ of respondents preferred the use of any simulated teaching aids or alternative methods of learning. Despite the prolonged suspension of clinical training is likely to impact the clinical competence and confidence of dental students, this might also encourage students to engage in selfdirected learning to keep up with the latest academic developments [20]. In this study, most of the students $(71.4 \%)$ stated that they made individual efforts to support learning is an indicator of this positive effect.

In a meta-analysis, which presented the prevalence of depression in the community from 30 countries between 1994 and 2014, the prevalence of depression was reported significantly higher in females [24]. A study about the mental health of undergraduate students by Kecojevicb et al. [4] was reported that the high levels of depression were associated with employment losses and with difficulties in focusing on academic work and higher levels of perceived stress were more likely to see in females, similar to the present study. Liu et al. [25] also presented that the females appeared to be more prone to anxiety than males, which may be related to their sensitivity to psychological stress. Traditional masculinity and femininity self-concepts can lead to 
different expressions of emotions and attitudes towards life experiences. Therefore, female students might be more likely to be affected by a stress-triggering factor such as the COVID-19 outbreak.

The obtained data by this study showed that the COVID-19 pandemic affected students' postgraduate career perspectives by $29.3 \%$ and a considerable part of participants (33.2\%) also stated as undecided. Most of the participants $(41.3 \%)$ wanted to work in academia. However, in a study evaluating fifth-year dental students' career planning, $39 \%$ of the participants stated that they wanted to work in private, $38 \%$ in public, and $17 \%$ in the academic field [26]. Differences between dental students in terms of social, economic and cultural backgrounds are likely to impact their professional career plans. Furthermore, dentistry is an undergraduate program that includes intensive theoretical and practical training, which can be challenging for students. This may affect students' desire to specialize. In a study, while $21 \%$ of the participants decided to specialize before dental school, only $1 \%$ stated that they would like to specialize in the fourth year. However, students ranked academics second as the field with the best future in terms of the overall profession [27]. The reason why students tend to specialize in the academic field in the present study may be that by continuing their education while the virus is active and they may want to be away from the field as much as possible. $82.6 \%$ of them stated feeling fear that they may be exposed to the virus while performing their profession. Furthermore, students' concern will earn less money after graduation $(48.6 \%$ of the participants) may have affected their career planning.

The biological and physical repercussions of a pandemic are the focus; however, mental health problems related to the pandemic are also crucial issues that need to be addressed. Cognitive behavior therapy (CBT) that enhancing stress management is useful during a pandemic [28]. CBT should be delivered via the internet (ICBT); it is cost-effective and prevents the spread of COVID-19 [29]. ICBT can also treat psychiatric symptoms such as insomnia [30].

Besides probably negative aspects of the COVID-19 pandemic on the psychological health of clinical students, the involvement of the students in the control and prevention of the disease has certain advantages. Senior medical students show sufficient clinical and practical capabilities since they have various transferable skills, such as logical reasoning, observation, listening, critical appraisal, and decision making, gained through their practical training programs. Furthermore, medical students are able to perform well under high pressure and handle a heavy workload with the gains they have achieved throughout their education life. However, becoming familiar with the work as well as the changing environment might take quite a long time, especially in such a pandemic as COVID-19 [31].

Although this study handles the psychological effects of the lockout caused by COVID-19 on dental students from different perspectives, it does not include the comparison of the obtained data with other college students in different fields. This constitutes the limitation of the study. Comparative data can be useful in assessing the effect of different educational models and study fields on students' psychological health. Therefore, in this study, the obtained data was concluded by comparing it with the literature data. Furthermore, this study mainly used self-reported questionnaires to measure psychiatric symptoms and did not make a clinical diagnosis. The gold standard for establishing psychiatric diagnosis involved a structured clinical interview and functional neuroimaging [32,33].

\section{Conclusion}

This study presented that the psychological health of senior undergraduate dental students has been affected adversely due to COVID-19 Pandemic. High depression, anxiety, and stress scores of the students 
were associated with the challenges in learning, concerning insufficient professional competence, and financial difficulties and exposure risk of the virus after graduation. Supporting learning by proposing different educational models that will enable students to continue their education safely, increasing knowledge of students to avoid the risk of virus exposure, providing personal protective equipment in clinical practice, and providing support for career planning might help to restore students' psychological health.

\section{Authors' Contributions}

GK (D) https://orcid.org/O000-0003-4569-7174 $\begin{aligned} & \text { Conceptualization, Methodology, Formal Analysis, Investigation, Data Curation, Writing - } \\ & \text { Original Draft and Writing - Review and Editing. }\end{aligned}$
All authors declare that they contributed to critical review of intellectual content and approval of the final version to be published.

\section{Financial Support}

None.

\section{Conflict of Interest}

The authors declare no conflicts of interest.

\section{Data Availability}

The data used to support the findings of this study can be made available upon request to the corresponding author.

\section{Acknowledgements}

Thanks for all the contributors and participants.

\section{References}

[1] Choi EPH, Hui BPH, Wan EYF. Depression and anxiety in Hong Kong during COVID-19. Int J Environ Res Public Health 2020; 17(10):3740. https://doi.org/10.3390/ijerph 17103740

[2] Dubey S, Biswas P, Ghosh R, Chatterjee S, Dubey MJ, Lahiri D, et al. Psychosocial impact of COVID-19. Diabetes Metab Syndr 2020; 14(5):779-88. https://doi.org/10.1016/j.dsx.2020.05.035

[3] Tran BX, Nguyen HT, Le HT, Latkin CA, Pham HQ, Vu LG, et al. Impact of COVID-19 on economic well-being and quality of life of the Vietnamese during the national social distancing. Front Psychol 2020; 11:565153. https://doi.org/10.3389/fpsyg.2020.56515

[4] Kecojevic ABC, Sullivan M, Davi NK. The impact of the COVID-19 epidemic on mental health of undergraduate students in New Jersey, cross-sectional study. PloS one 2020; 15(9):e0239696. https://doi.org/10.1371/journal.pone.0239696

[5] Gerreth K, Chlapowska J, Lewicka-Panczak K, Sniatala R, Ekkert M, Borysewicz-Lewicka M. Self-evaluation of anxiety in dental students. Biomed Res Int 2019; 2019:6436750.

[6] Basudan S, Binanzan N, Alhassan A. Depression, anxiety and stress in dental students. Int J Med Educ 2017; 8:17986. https://doi.org/10.5116/ijme.5910.b961

[7] Cooper CL, Watts J, Kelly M. Job satisfaction, mental health, and job stressors among general dental practitioners in the UK. Br Dent J 1987; 162(2):77-81. https://doi.org/10.1038/sj.bdj.4806030

[8] Rehmani N, Khan QA, Fatima SS. Stress, anxiety and depression in students of a private medical school in Karachi, Pakistan. Pak J Med Sci 2018; 34(3):696-701. https://doi.org/10.12669/pjms.343.14664

[9] Wang C, Pan R, Wan X, Tan Y, Xu L, McIntyre RS, et al. A longitudinal study on the mental health of general population during the COVID-19 epidemic in China. Brain Behav Immun 2020; 87:40-8. https://doi.org/10.1016/j.bbi.2020.04.028

[10] Le HT, Lai AJX, Sun J, Hoang MT, Vu LG, Pham HQ, et al. Anxiety and depression among people under the nationwide partial lockdown in Vietnam. Front Public Health 2020; 8:589359. https://doi.org/10.3389/fpubh.2020.589359

[11] Tee ML, Tee CA, Anlacan JP, Aligam KJG, Reyes PWC, Kuruchittham V, et al. Psychological impact of COVID-19 pandemic in the Philippines. J Affect Disord 2020; 277:379-91. https://doi.org/10.1016/j.jad.2020.08.043

[12] Stormon N, Ford PJ, Kisely S, Bartle E, Eley DS. Depression, anxiety and stress in a cohort of Australian dentistry students. Eur J Dent Educ 2019; 23(4):507-14. https://doi.org/10.1111/eje.12459 
[13] Kaparounaki CK, Patsali ME, Mousa DV, Papadopoulou EVK, Papadopoulou KKK, Fountoulakis KN. University students' mental health amidst the COVID-19 quarantine in Greece. Psychiatry Res 2020; 290:113111. https://doi.org/10.1016/j.psychres.2020

[14] Liang SW, Chen RN, Liu LL, Li XG, Chen JB, Tang SY, et al. The psychological impact of the COVID-19 epidemic on Guangdong college students: The difference between seeking and not seeking psychological help. Front Psychol 2020; 11:2231. https://doi.org/10.3389/fpsyg.2020.02231.

[15] Cao W, Fang Z, Hou G, Han M, Xu X, Dong J, et al. The psychological impact of the COVID-19 epidemic on college students in China. Psychiatry Res 2020; 287:1 12934. https://doi.org/10.1016/j.psychres.2020.112934

[16] Odriozola-Gonzalez P, Planchuelo-Gomez A, Irurtia MJ, de Luis-Garcia R. Psychological effects of the COVID-19 outbreak and lockdown among students and workers of a Spanish university. Psychiatry Res 2020; 290:113108. https://doi.org/10.1016/j.psychres.2020.113108

[17] Xiong J, Lipsitz O, Nasri F, Lui LMW, Gill H, Phan L, et al. Impact of COVID-19 pandemic on mental health in the general population: A systematic review. J Affect Disord 2020; 277:55-64. https://doi.org/10.1016/j.jad.2020.08.001

[18] Wang C, Pan R, Wan X, Tan Y, Xu L, Ho CS, et al. Immediate psychological responses and associated factors during the initial stage of the 2019 Coronavirus Disease (COVID-19) epidemic among the general population in China. Int J Environ Res Public Health 2020; 17(5):1729. https://doi.org/10.3390/ijerph 17051729

[19] Atas O, Talo Yildirim T. Evaluation of knowledge, attitudes, and clinical education of dental students about COVID19 pandemic. PeerJ 2020; 8:e9575. https://doi.org/10.7717/peerj.9575

[20] Loch C, Kuan IBJ, Elsalem L, Schwass D, Brunton PA, Jum'ah A. COVID-19 and dental clinical practice: Students and clinical staff perceptions of health risks and educational impact. J Dent Educ 2020; 85(1):44-52. https://doi.org/10.1002/jdd.12402

[21] Mukhtar K, Javed K, Arooj M, Sethi A. Advantages, Limitations and Recommendations for online learning during COVID-19 pandemic era. Pak J Med Sci 2020; 36(COVID19-S4):S27-S31. https://doi.org/10.12669/pjms.36.COVID19-S4.2785

[22] Iyer P, Aziz K, Ojcius DM. Impact of COVID-19 on dental education in the United States. J Dent Educ 2020; 84(6):718-22. https://doi.org/10.1002/jdd.12163

[23] Kharma MY, Koussa B, Aldwaik A, Yaseen J, Alamari S, Alras H, et al. Assessment of anxiety and stress among dental students to return to training in dental college in COVID-19 era. Eur J Dent 2020; 14(S 01):S86-S90. https://doi.org/10.1055/s-0040-1717052

[24] Lim GY, Tam WW, Lu Y, Ho CS, Zhang MW, Ho RC. Prevalence of depression in the community from 30 countries between 1994 and 2014. Sci Rep 2018; 8(1):2861. https://doi.org/10.1038/s41598-018-21243-x

[25] Liu X, Luo WT, Li Y, Li CN, Hong ZS, Chen HL, et al. Psychological status and behavior changes of the public during the COVID-19 epidemic in China. Infect Dis Poverty 2020; 9(1):58. https://doi.org/10.1186/s40249-020-00678-3

[26] Alrashdan MS, Alazzam M, Alkhader M, Phillips C. Career perspectives of senior dental students from different backgrounds at a single Middle Eastern institution. BMC Med Educ 2018; 18(1):283. https://doi.org/10.1186/s12909-018-1386-9

[27] Dhima M, Petropoulos VC, Han RK, Kinnunen T, Wright RF. Dental students' perceptions of dental specialties and factors influencing specialty and career choices. J Dent Educ 2012; 76(5):562-73.

[28] Ho CS, Chee CY, Ho RC. Mental Health Strategies to combat the psychological impact of COVID-19 beyond paranoia and panic. Ann Acad Med Singap 2020; 49(3):155-60.

[29] Zhang MW, Ho RC. The cost effective solution for internet cognitive behavioral therapy (I-CBT) interventions. Technol Health Care 2017; 25(1):163-165. https://doi.org/10.3233/THC-161261.

[30] Soh HL, Ho RC, Ho CS, Tam WW. Efficacy of digital cognitive behavioural therapy for insomnia: a meta-analysis of randomised controlled trials. Sleep Med 2020; 75:315-25. https://doi.org/10.1016/j.sleep.2020.08.020

[31] Tran BX, Vo LH, Phan HT, Pham HQ, Vu GT, Le HT, et al. Mobilizing medical students for COVID-19 responses: Experience of Vietnam. J Glob Health 2020; 10(2):020319. https://doi.org/10.7189/jogh.10.020319

[32] Husain SF, Yu R, Tang TB, Tam WW, Tran B, Quek TT, et al. Validating a functional near-infrared spectroscopy diagnostic paradigm for major depressive disorder. Sci Rep 2020; 10(1):9740. https://doi.org/10.1038/s41598-020-66784-2

[33] Ho CSH, Lim LJH, Lim AQ, Chan NHC, Tan RS, Lee SH, et al. Diagnostic and predictive applications of functional near-infrared spectroscopy for major depressive disorder: a systematic review. Front Psychiatry 2020; 11:378. https://doi.org/10.3389/fpsyt.2020.00378 